\title{
ECO-FRIENDLY JUTE PROCESSING IN BANGLADESH
}

\author{
Hasin M. Feroz and J. Nahar \\ M. Rahman* \\ Department of Chemical Engineering \\ Bangladesh University of Engineering and Technology, BUET, Dhaka-1000
}

\begin{abstract}
Bangladesh is one of the largest exporters of jute which is commonly processed with mineral Jute Batching Oil (JBO). $J B O$-processed jute products (especially food grade packaging item) have poor acceptability worldwide mainly due to their unpleasant odor, texture and the possible presence of carcinogenic compounds Foreign market has demanded replacement of mineral JBO and it is high time not to ignore the market signal. Therefore, primary focus of this research work was to develop an alternative to mineral JBO that will be eco-friendly in addition to retaining desired properties, particularly strength and longevity and will sustain and expand Bangladesh's share of the global jute market. The study was conducted by processing jute with castor oil as well as the traditional mineral JBO. The jute properties such as strength, brightness, whiteness and moisture content were evaluated and the results interpreted using FT-IR (Fourier Transform Infra Red Spectrum) and SEM (Scanning Electron Microscope) analysis. While castor oil is eco-friendly and relatively odor-free, the results indicate that it has lower strength than mineral JBO processed jute products possibly due to enhanced biodegradability.
\end{abstract}

Key words: Batching; JBO; Castor Oil; FT-IR; SEM; Biodegradability

\section{Introduction}

Jute is the most versatile natural fiber which seconds only cotton in annual production. It is mainly composed of cellulose, hemicellulose and lignin and falls in the category of bast fiber. Jute grows best in rain-fed, hot and humid subtropical conditions which is common to eastern parts of the Indian subcontinent [11].

The climatic conditions of Bangladesh are suitable for harvesting jute, enabling the country to be one of the top exporters of jute. In the year of 2007-08, Bangladesh produced about 990,000 tons of raw jute of which it exported 477,000 tons. Thus in these years, Bangladesh held a share of $63.26 \%$ of the global exports of jute goods [7].

With the worldwide emphasis on the use of eco-friendly jute products, especially for packaging of food materials such as coffee beans and cocoa beans, it has been become essential to focus on the environment and health aspects of different stages of jute processing [4].

Although, jute is a naturally occurring and therefore ecofriendly fiber, one of the processing stages involves addition of an external agent. This is commonly known as the piling/batching stage in which a lubricating oil emulsion is applied on the retted jute. Traditionally, petroleum-based oil, JBO is used for this purpose. Certain properties of JBO such as its unpleasant odor and presence of potential promoters of carcinogenesis is considered by some to be a potential health-hazard. The diffusion of these odorous and toxic compounds from JBO-processed goods limits their acceptability in the international market. This inevitably creates the need to find suitable alternatives to JBO which will retain the desired properties of jute while making the process more eco-friendly [1,9].

Batching involves treating the retted jute fiber with an emulsion of oil in water which softens the fiber through removal of lignin. The oil in the emulsion forms a thin protective layer around the fiber which prevents rapid evaporation of water and acts as a lubricant thus reducing fiber breakage in various stages of jute processing. After softening, the jute bundles are stacked and kept under cover for a certain period of time (conventionally 48 hours) in a process known as piling. Absorption of moisture in this stage results in the evolution of heat which encourages microbial growth and consequent decay/softening of jute [11].

Brightness and whiteness are properties that characterize the physical appearance of natural fibers like jute and enhance the aesthetic value of final jute products [10]. 
Jute is hygroscopic in nature owing to its significant hemicellulose content. Moisture content of jute is an important parameter as too low a moisture content would reduce its flexibility and increase breakage and loss of fibers; while too high a moisture content would encourage microbial growth and lead to rapid deterioration of the processed jute [11]. Typically jute absorbs $12-14 \%$ moisture by weight at $65 \pm 5 \%$ Relative Humidity $(\mathrm{RH})$ with the value increasing with increasing RH [5].

The use of processed jute for a particular purpose will be determined by its strength. Therefore, strength is an important criteria for characterizing jute products and assessing their quality and service life.

Castor oil is a vegetable oil which can be a potential alternative to mineral JBO. Therefore, batching was carried out using both mineral JBO and castor oil and their effects on various physical and chemical properties of processed jute were observed and compared.

\section{Experimental}

\subsection{Materials}

In this work, locally produced ' $B$ ' grade Bangla white jute [11] was used as the natural fiber source. Locally produced mineral Jute Batching Oil (JBO) from Padma Oil Company Ltd., Bangladesh and Castor oil (Indian origin) were used as batching oil for same type of jute. Commercial emulsifier, Nonidet P-40 (Indian origin), was used to emulsify the batching oils in batching process. Table 1 shows the physical properties of the batching oils used.

Table 1. Physical properties of JBO and Castor Oil [4]

\begin{tabular}{lcc}
\hline \multicolumn{1}{c}{ Parameters } & JBO & Castor Oil \\
\hline Specific gravity & 0.87 & 0.95 \\
Flash point & 125 & 298 \\
Pour point & 32 & 15 \\
Odor & Kerosenic & Mild \\
Color & Reddish brown & Pale yellow \\
\hline
\end{tabular}

\subsection{Methodology}

\subsubsection{Batching}

The batching emulsions were prepared by blending oil with water in presence of an emulsifying agent. The emulsions were prepared using a pneumatic mixer and used in amounts of $25 \%$ by weight of raw jute.

Table 2: The emulsion compositions in wt \%

\begin{tabular}{lcc}
\hline \multicolumn{1}{c}{ Emulsion Composition } & JBO & Castor Oil \\
\hline Oil & 20.0 & 18.0 \\
Water & 79.9 & 81.9 \\
Nonidet P-40 (emulsifier) & 0.1 & 0.1 \\
\hline
\end{tabular}

After batching, the softened jute sent through the carding, drawing and spinning stages which helped to untangle and draw the jute fibers and spin them into threads, also known as yarn. The block diagram for the process is shown in figure 1 .

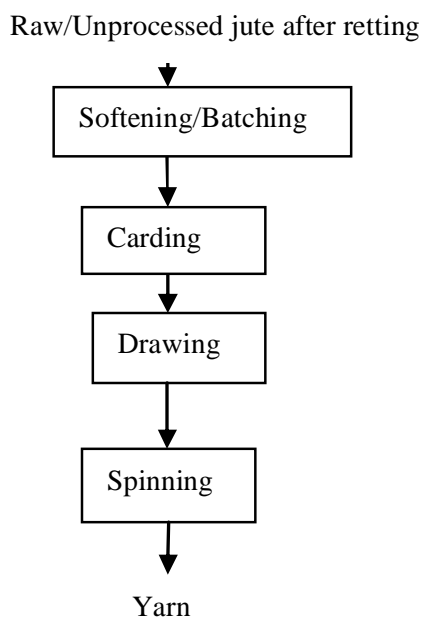

Fig. 1: Stages of jute processing for yarn production

\subsubsection{Property evaluation}

Properties (brightness, whiteness, moisture content, tensile strength, surface topography, IR spectroscopy) were evaluated for raw and batched jute to compare the after effect of batching oils. All numerical results were evaluated in terms of mean $(\mu)$ and standard deviation $(\sigma)$

Brightness and whiteness: Brightness and whiteness are two properties that characterize the physical appearance of jute. Brightness is the percentage reflectance of blue light only at a wavelength of $457 \mathrm{~nm}$, while whiteness refers to the extent to which any material diffusely reflects light of all wave lengths of the visible spectrum [10]. Both these parameters were measured by a standardized Photovolt Reflectance Meter, Model 577, Testing Machines Inc., USA. The samples were conditioned at a temperature of $27 \pm 2^{\circ} \mathrm{C}$ and $65 \pm 2 \% \mathrm{RH}$ for a minimum of 24 hours before testing.

Moisture content: Moisture content (MC) is the ratio of the weight of moisture in the sample and total weight of the sample. Moisture content was measured by heating the samples in an oven over a period of 6 hours at $105^{\circ} \mathrm{C}$ [2].

$$
\mathrm{MC}=\frac{\text { weight of moisture }}{\text { dry weight }+ \text { weight of moisture }} \times 100
$$

Tensile strength: Tensile Strength Tester was used for measuring the maximum breaking load of the yarns processed by different batching oils. Pressley Fiber Strength Tester, F215, SDL Atlas, Inc., USA was used to measure the strength of fibers in terms of the Pressley Index (P.I) [3].

P. I. $=\frac{\text { Breaking Load }(\mathrm{lb})}{\text { Bundle weight }(\mathrm{mg})}$ 
All stages of jute processing and above mentioned tests were conducted at BJRI (Bangladesh Jute Research Institute), Dhaka.

Surface topography: Surface topography relates to various features and details of the surface of a particular jute fiber. The SEM(Scanning Electron Microscope), FEI Quanta Inspect, Model S50 of Atomic Energy Centre, Dhaka was used at magnifications of 200 and 1000 times to observe the surface topography of the fiber samples.

Infrared spectroscopy: Infrared spectroscopy uses the principle of absorption of specific wavelengths by specific functional groups/compounds to correctly identify them and their relative proportions in a given substance [7]. The infra red spectrum of the raw and batched jute fibers was observed using the JASCO FT-IR 6300 Series Spectrometer.

\section{Results and Discussions}

\subsection{Macroscopic properties}

Brightness of raw jute was found to be the highest among all samples due to its intact surface. The measured brightness of the batched fibers in decreasing order is given by JBO followed by castor oil. Brightness results are shown in table 3 .

Table 3. Brightness of jute fiber and yarn

\begin{tabular}{ccccccc}
\multicolumn{7}{c}{ [Raw jute fiber: $\mu=41.2 \%, \sigma=4.6 \%]$} \\
\cline { 2 - 7 } $\begin{array}{c}\text { Oil } \\
\text { used }\end{array}$ & $\begin{array}{c}\text { After } \\
\text { Batching }\end{array}$ & \multicolumn{2}{c}{$\begin{array}{c}\text { Breaker } \\
\text { Card }\end{array}$} & \multicolumn{2}{c}{ Yarn } \\
\cline { 2 - 7 } & $\boldsymbol{\mu}$ & $\boldsymbol{\sigma}$ & $\boldsymbol{\mu}$ & $\boldsymbol{\sigma}$ & $\boldsymbol{\mu}$ & $\boldsymbol{\sigma}$ \\
\hline JBO & 38.7 & 5.6 & 40.4 & 1.2 & 37.6 & 2.3 \\
$\begin{array}{c}\text { Castor } \\
\text { oil }\end{array}$ & 31.7 & 3.4 & 34.7 & 2.7 & 19.4 & 1.7 \\
\hline
\end{tabular}

The measured whiteness of jute fibers after batching in decreasing order is given by castor oil, raw jute and finally JBO. Whiteness results are shown in table 4 .

Table 4. Whiteness of jute fiber and yarn [Raw jute fiber: $\mu=28.3 \%, \sigma=3.0 \%$ ]

\begin{tabular}{cccccccc}
\hline & \multicolumn{6}{c}{ Whiteness (\%) } \\
\cline { 2 - 7 } Oil used & $\begin{array}{c}\text { After } \\
\text { Batching }\end{array}$ & \multicolumn{2}{c}{$\begin{array}{c}\text { Breaker } \\
\text { Card }\end{array}$} & \multicolumn{1}{c}{ Yarn } \\
\cline { 2 - 7 } & $\boldsymbol{\mu}$ & $\boldsymbol{\sigma}$ & $\boldsymbol{\mu}$ & $\boldsymbol{\sigma}$ & $\boldsymbol{\mu}$ & $\boldsymbol{\sigma}$ \\
\hline JBO & 24.7 & 2.8 & 31.5 & 3.1 & 24.6 & 2.5 \\
$\begin{array}{c}\text { Castor } \\
\text { oil }\end{array}$ & 37.2 & 5.1 & 43.7 & 2.4 & 36 & 2.1 \\
\hline
\end{tabular}

The lower brightness and whiteness of the treated fibers can be attributed to the degradation or removal of lignin from the fiber surface following the batching process.
Moisture contents of raw jute and processed yarn are shown in table 5 .

Table 5. Moisture content (wt\%) of raw jute and yarns

\begin{tabular}{ccc} 
Raw jute fiber & $\begin{array}{c}\text { JBO treated } \\
\text { yarn }\end{array}$ & $\begin{array}{c}\text { Castor oil } \\
\text { treated yarn }\end{array}$ \\
\hline 9.7 & 10.4 & 10.0 \\
\hline
\end{tabular}

The comparative effects of different batching oils on the strength of jute fibers and yarns were studied. The better performance among the treated ones was observed for JBO in the yarn stage which was closely followed by castor oil. Although the raw jute fiber had the highest fiber strength, threading of raw jute without processing is not desirable due to its poor machinability. The results obtained are given in table 6 .

Table 6. Strength of fibers and yarns after treatment [Raw jute fiber: $\mu=15.1 \mathrm{lb} / \mathrm{mg}, \sigma=2.50 \mathrm{lb} / \mathrm{mg}$ ] Fiber strength: P.I.

\begin{tabular}{ccccccc} 
Oil & \multicolumn{4}{c}{$\begin{array}{c}\text { Fiber strength: P.I. } \\
\text { (lb/mg) }\end{array}$} & \multicolumn{2}{c}{$\begin{array}{c}\text { Yarn strength } \\
\text { used }\end{array}$} \\
\cline { 2 - 5 } & $\begin{array}{c}\text { After } \\
\text { Batching }\end{array}$ & \multicolumn{2}{c}{$\begin{array}{c}\text { Breaker } \\
\text { Card }\end{array}$} & & \\
\cline { 2 - 6 } & $\boldsymbol{\mu}$ & $\boldsymbol{\sigma}$ & $\boldsymbol{\mu}$ & $\boldsymbol{\sigma}$ & $\boldsymbol{\mu}$ & $\boldsymbol{\sigma}$ \\
\hline JBO & 7.32 & 0.80 & 6.22 & 1.53 & 7.53 & 1.72 \\
$\begin{array}{c}\text { Castor } \\
\text { oil }\end{array}$ & 6.80 & 1.45 & 6.36 & 0.67 & 6.13 & 1.41 \\
\hline
\end{tabular}

\subsection{Microscopic properties}

SEM micrographs give an up-close, three-dimensional picture of the jute samples as shown in fig. 2 and fig. 3 .

Samples for SEM were prepared by separating individual fibers manually. As a result, the interlinkages between the fibers were torn and these were observed as protrusions in the micrographs. As the raw jute was untreated it was stiffer with stronger interlinkages and the number of fibrils protruding from its surface was the largest as seen in fig.2. In addition, the compactness of the cell bundles of the raw jute sample was the poorest as seen in fig. 3 .

The treated fibers showed better performance than raw jute fiber. This can be attributed to the removal of lignin in the softening stage which made the fibers more machinable thereby improving their spinnablity in the yarn making process. The surface smoothness for JBO was better than that of castor oil. This resulted in greater surface reflectance of JBO-treated jute fiber as observed in the brightness test.

Among the fibers that were treated, castor oil treated fibers/cell bundles were dense with very little void space and relatively uniform cylindrical shape. While this ought to have resulted in higher yarn strength, the relatively lower diameter of these fibers resulted in lower yarn strength than those treated by JBO. 


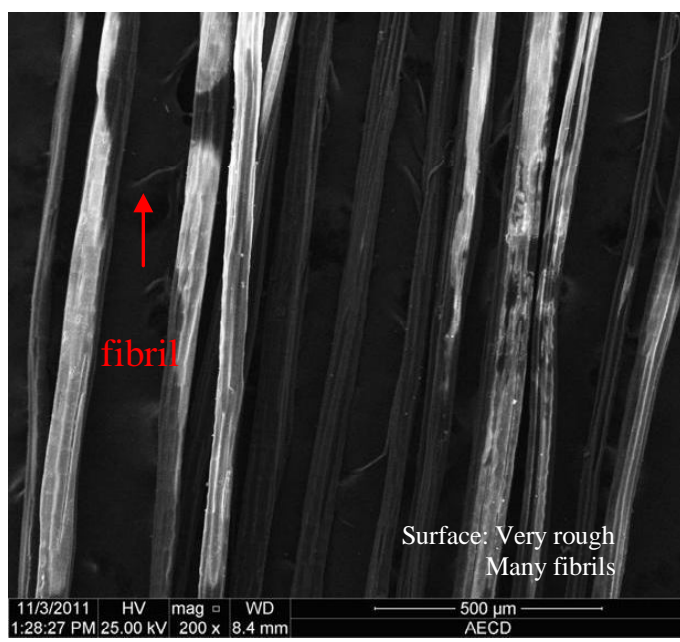

a)

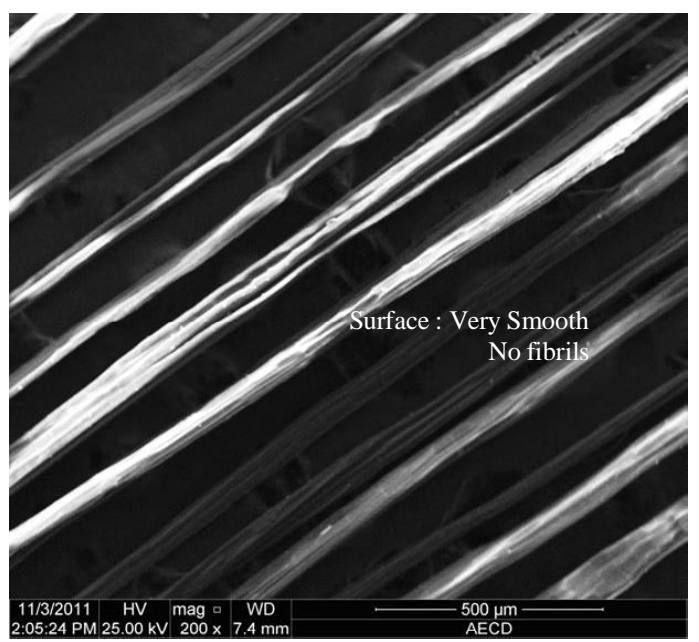

b)

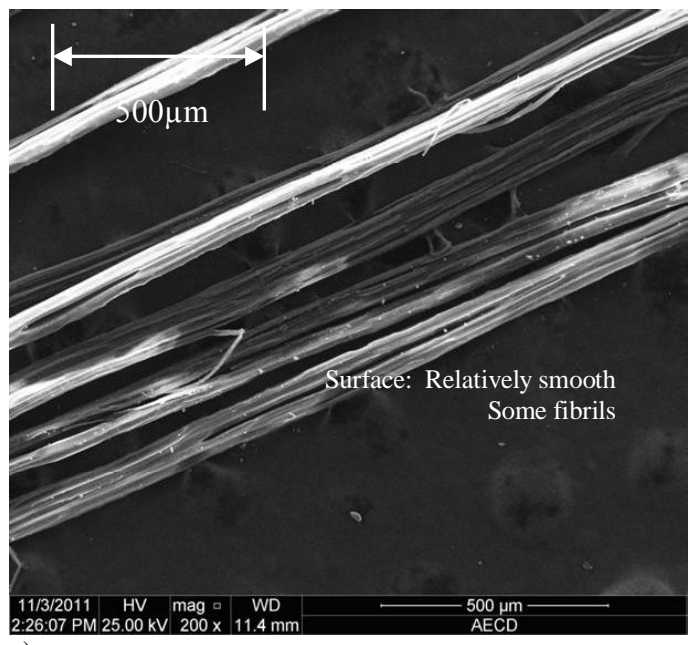

c)

Fig. 2: Fibers at 200X magnification

a) Raw jute fiber b) JBO processed jute fiber c)

Castor oil processed jute fiber

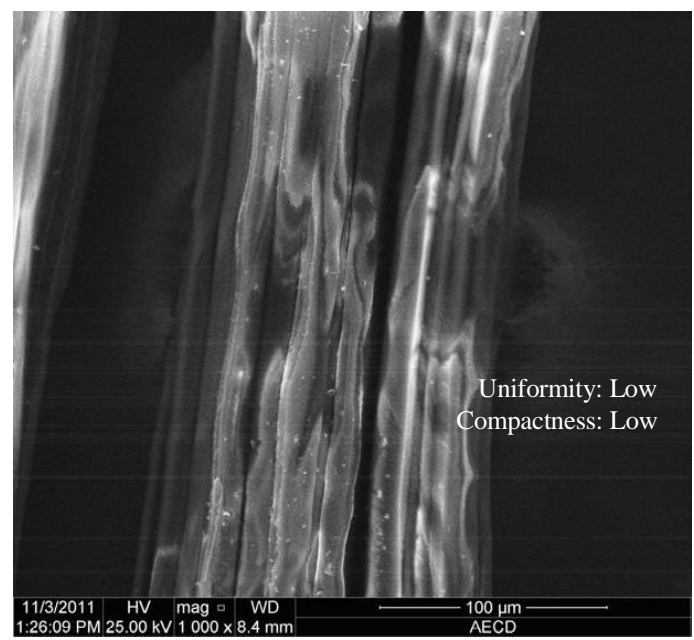

a)

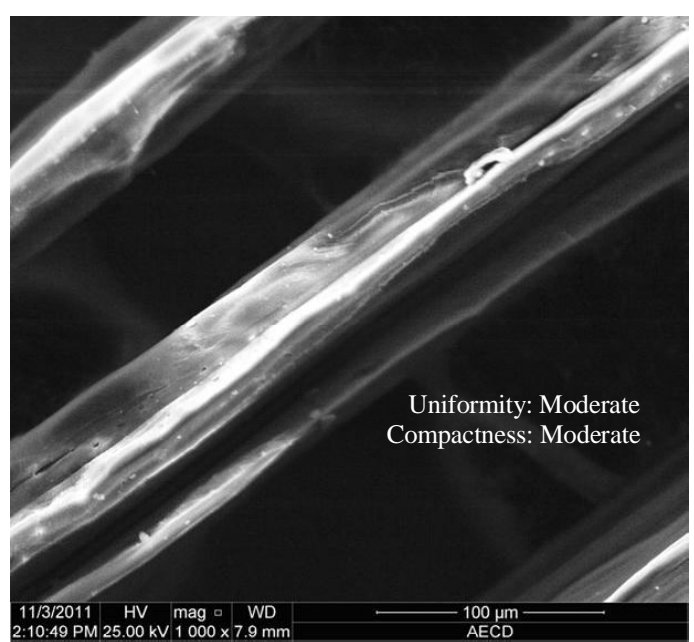

b)

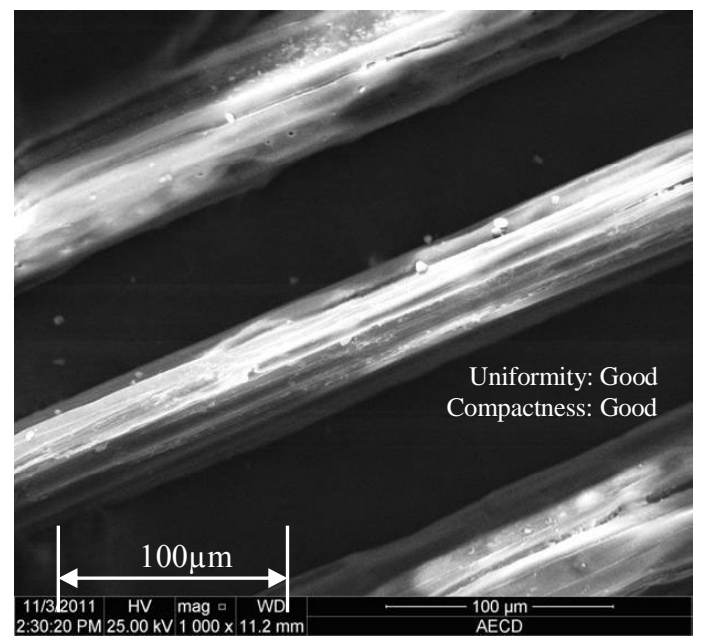

c)

Fig. 3: Fibers at 1000X magnification

a) Raw jute fiber b) JBO processed jute fiber c)

Castor oil processed jute fiber 
The IR spectrum of castor oil treated fibers showed the lowest relative absorbance possibly due to the rapid fiber degradation on treating with castor oil. This is in agreement with the low tensile strength of castor oil treated fibers and yarns.

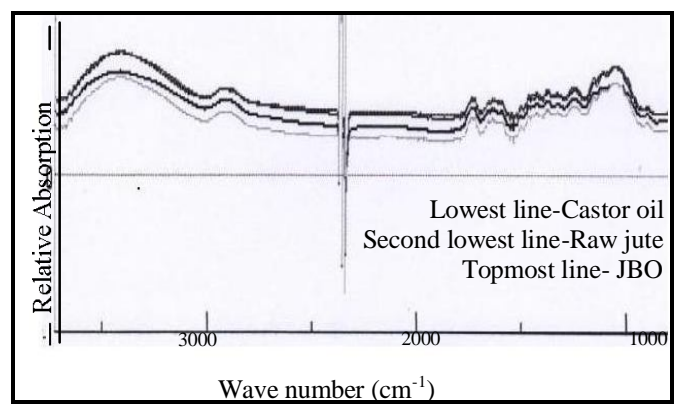

Fig. 4: FT-IR spectrum of the raw jute and treated jute fibers.

As the last and hence the oldest batch of jute was treated with castor oil, another possible explanation for its IR spectrum could be the decline in fiber quality due to the ageing effect and changes in conditions of surroundings such as temperature, humidity, etc.

\section{CONCLUSION}

Inspite of the adverse effects of JBO, it remains the predominant choice for jute processing in Bangladesh. However, with the worldwide emphasis on 'eco-friendly' products, it has become essential for Bangladesh to respond to the changing market scenario, possibly through the use of vegetable oils. While vegetable oils, like castor oil are eco-friendly, they may also enhance the possibility of rapid degradation of the processed jute. Thus additional processing may be needed to enhance the rot-resistant property and hence enhance the usability of castor-oil treated jute products.

\section{REFERENCE}

1. Agarwal et. al(1988), Evaluation of carcinogenic effect of jute batching oil (JBO-P) fractions following topical application to mouse skin, PubMed.gov, National Center for Biotechnology and Information(NCBI), 62(6), pp. 406-10

2. Annual Technical Report (2010-2011), Bangladesh Jute Research Institute, pp.7-11

3. Booth, J.E. (1968), Principle of Textile Testing, Butterworth Heinemann Ltd., U.K.

4. Chakrabarti, S.K., Eco-friendly processing of jute and allied fibres, Indian jute industries' research association, 17 Taratala road, Kolkata 700088 .
5. Roy, Gautum and Saha, S.C.(2010), Development of digital moisture meter for jute fiber and its products, Indian Journal of Fibre and Textile Research, 36, pp. 178-182

6. Dilruba et. al (2010), Production of jute yarns with low content of unsaponifiable matters, Daffodil International University Journal of Science and Technology, 5 (1), pp. 10-18

7. FAO; BJRI, Jute Commissioner of India; Statistics, IJSG

8. IR spectroscopy Tutorial, Department of Chemistry, Colorado State University, viewed 3November,2011,

<http://www.orgchem.colorado.edu/hndbksupp ort/irtutor/tutorial.htm>

9. Mehrotra et. al (1988), Carcinogenic property of JBO (P) variety of Jute Batching Oil, Drug and Chemical Toxicology, 11(2), pp. 181-193

10. Properties of paper, viewed 13 October, 2004, <http://www.paperonweb.com/paperpro.htm>

11. Roy, S. (2010), Jute basics, International Jute Study Group, Bangladesh. 